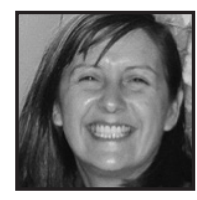

\title{
Who Are You? On Being Half Indian and Half White
}

\author{
Andrea Fiss, University of Saskatchewan
}

\section{ABSTRACT}

Coming from a mixed ethnic identity is difficult, particularly if the two identities of which you are mixed look physically very different. Through personal narratives, the author makes visible how one's appearance can determine how other people interpret one's identity. She examines challenges that arise when the messages one receives about one's identity are contradictory and relates these contradictory messages to the concept of social dominance. The author makes it apparent that place and community establish one's feelings about oneself. She concludes that an individual of mixed race cannot extract one ethnicity from the other; the individual will always be both.

\section{Foreword}

have chosen to use the words "Indian" and "white" in this article because those were the first words I knew and used. They are the words I use with family and friends, though not usually with others. Thomas King (2012) had this to say on the use of the words Indian and white:

When I was a kid, Indians were Indians. Sometimes Indians were Mohawks or Cherokees or Crees or Blackfoot or Tlingits or Seminoles. But mostly they were Indians. Columbus got blamed for the term, but he wasn't being malicious. He was looking for India and thought he had found it. He was mistaken, or course, and as time went on, various folks and institutions tried to make the matter right. Indians became Amerindians and Aboriginals and Indigenous People and American Indians. Lately, Indians have become First Nations in Canada and Native Americans in the 
United States, but the fact of the matter is that there has never been a good collective noun because there never was a collective to begin with. (p. xii)

In reference to the use of the word white, King (2012) said this, "Let's agree that within the confines of this book the term is neutral and refers to a general group of people as diverse and indefinable as 'Indians'" (p. xiv).

\title{
Who Are You? \\ On Being Half White and Half Indian
}

\author{
"Who are you?" \\ "I am Indian." \\ "Who are you?" \\ "I am white." \\ "Who are you?" \\ "I am half Indian and half white." \\ "Half? How could you be half?" \\ “Well, I tell ya. It's not easy.....
}

\section{On Being Half and Half}

Mirrors reflect, a lake reflects, a window reflects, a shiny new car reflects, a computer screen reflects, an icy road reflects, and people reflect. If we look closely enough in all of these things, we can see our reflection shining back at us. Sometimes our reflection is clear but other times our reflection is distorted. Sometimes our reflection is so distorted that it does not look like us at all. And sometimes what is reflected back matches our outside very well, but does not match our inside at all. That is what it feels like to be half and half. It is confusing at times, trying to fit that outside into that inside.

My dad is white and if you saw him you would know that he is white. My mom is Métis and if you saw her you would know that she is Indian. I have dark brown hair and brown eyes, but my skin is light and my features are ambiguous. If you saw me you would assume that I am white. At least, in my experience, that is what most people assume.

As a brand new teacher I found myself very often at school late into the evening, well after all of the sensible teachers had gone home. The caretaker was the only other person around and he would often stop in my classroom as he made his rounds. I welcomed his company as it gave me a much needed break. We would visit for a while before he would move on. This one time he told me a story about 
his neighbors, who were Indians. It was not a good story. When he had finished his story he declared quite dramatically, "I hate Indians." This reminded me that he did not know that I was Indian. I thought to myself, do I say nothing or do I tell him that I am Indian? I chose the latter.

\section{"Who are you?" \\ "I am white." \\ "At least that's what they told me."}

Identity is not only about who you see in that reflection, it also includes what others see when they look at you. People reflect. It is often in these experiences with others that I become conscious of both sides of my identity. That Indian side and that white side. Yet I am not completely one or the other. Although others may see me as white because of how I look on the outside, it does not reflect what I feel like on the inside. Richardson (2006) describes the process this way, "Metis identity is created through a process of social interaction and dialogic relationships between the inner world and the external world" (p. 57). That is what this story is about, attempting to create balance between that outward reflection and that inward self.

\section{On Being From One}

Perhaps before we go any further I should define what I mean by identity. "Identity' may be defined as the distinctive character belonging to any given individual, or shared by all members of a particular social category or group" (Rummens, 2001, p. 3). Put more simply, identity is what you answer when someone asks, "Who are you?" For many people identity formation is an unconscious, straightforward event.

Others [not from a racial minority], especially white [North] Americans, manifest ethnic and racial identity in mostly unconscious ways through their behaviors, values, beliefs and assumptions. For them, ethnicity is usually invisible and unconscious because societal norms have been constructed around their racial, ethnic, and cultural frameworks, values, and priorities and then referred to as "standard American [Canadian] culture" rather than as "ethnic identity." (Chavez \& Guido-Dibrito, 1999, p. 39)

Some identities are dominant and thus deemed to be more valuable than others. Societies which are based on social class always have an element of dominance. When we talk about social dominance, we are talking about a social hierarchy with a group at the top and a group at the bottom. The group at the top will have the most 
representation, within the highest ranks, of all major social institutions. The group at the bottom will have the least representation within the highest ranks, of all major social institutions (Sidanius \& Pratto, 1993). In Saskatchewan, it is quite evident that white people belong to the top group and Indian people belong to the bottom group.

Even for people from a racial minority, identity formation, while perhaps not an unconscious act, is still relatively straightforward. My husband is Indian and if you saw him you would know he is Indian. He comes from a Reservation. His parents are Indian, his grandparents were Indian. There are no questions for him. He knows who he is. $\mathrm{He}$ is Indian. This is not to say that he does not have any struggles with his identity. Coming from the "bottom" group in our society, he has not had a lot of opportunity to see himself or his culture reflected in the broader community. He has other pressures on his identity as well. The government in Canada has weighed in and defined Indian as a political identity and Indian status, along with band membership, is legislated federally. Even amongst Indian people there is a hierarchy. "The production of a cultural hierarchy, organized around notions of tradition and assimilated Indians, denigrates some identities and honors others" (St. Denis, 2007, p. 1081). So, if you speak your language, you are seen to be more Indian than a person who does not speak his or her language. Yet, even with all of this, my husband can confidently, and without hesitation, answer "I am Indian" when someone asks him who he is.

\section{Who Are You?}

Our identity is formed over time by identity schema. "Self-schemata are cognitive generalizations about the self, derived from past experience, that organize and guide the processing of self-related information contained in the individual's social experiences" (Markus, 1977, p. 64). Self-identity, our identity schema, is something that develops over time, with experience. Our experience, our stories, fit into our schema. Identity formation is a social experience which involves other people. Other people can be our immediate family, our extended family, our peers, and members of the larger community. Our earliest experiences, those experiences that help us begin to form our identity schema, start with our families in our home.

I grew up in a small northern mining town. Lots of new Canadians found a home in the north; in the mines. My father came, like many, off the farm to the north. Where good paying jobs were plentiful. My father's family lived far away in southern Alberta. My mother is Métis and her family lived in the North before the mining boom. It was my mother's family that I grew up surrounded by. My Auntie Rose lived close to us. I had only to walk through my Auntie Margie's yard, across the road, and then I was 
at my Auntie Rose's house. I enjoyed visiting my Auntie Rose. I loved to talk when I was young and so did she, so we got along quite well. I have always been interested in history and learning about my family history. When I visited my aunt she would show me old photo albums. She would tell me who this person was and who that person was. I would listen intently. The faces that I saw in those pictures, faces of my family, were brown. They were Indian.

When I looked in a mirror, the face that I saw reflected back at me was Indian. I did not see a white person. I saw a face that matched my mother's family. But my father also had some influence. He was the head of the household, as they said back then. In many ways my home life mimicked a traditional white, middle-class lifestyle.

On Sunday mornings we would rise early and dress in our best clothes for church. After church, we would go home for Sunday brunch. It was only on Sundays that my father would cook: eggs, pancakes, bacon, toast, the works. After brunch we would go for a Sunday drive around town. Other families would be out, driving around town. In a small town when you pass a car, you wave. Everyone had their own individual wave: a full wave, a fast wave, a wave that looked more like a salute. My father would open and then close his hand while leaving it on the steering wheel, as he gave his head a nod. That was his wave. We would then stop at the drive-in, a little fast-food stand that sold ice cream. Other families would be stopped here and lots of visiting would go on. We would all get a "Nutty buddy" ice cream and then continue on our drive around town, before heading home to watch The Wonderful World of Disney.

\section{"Who are you?" \\ "I am Indian. I am White." \\ At least that's what they told me.}

There is some contradiction in these experiences. Although I saw myself as an Indian, my lifestyle was more consistent with white culture. Coming from two distinct places creates some duality inside. It is like inside me I have this Indian self and this white self and they usually get along and mix quite well without any questions. But at other times that Indian self and that white self are pulled apart and I am forced to look at and examine these two sides separately. Am I Indian or am I white? I wonder why I cannot be both. 


\section{When Half and Half Does Not Equal One}

When we consider the issue of Social Dominance (SD) we find that, "The entire reasoning of SD theory rests on the simple assumption that different ethnic groups may reliably be ranked along a single social status continuum" (Sidanius \& Pratto, 1993, p. 182). Within this continuum we would find white on one side and Indian on the other side, with other social/cultural groups in between. Part of the struggle with being half white and half Indian is that there is such a large gap between these two groups. This polarization is what creates tension.

Grade 4 was a very good year; I remember many things. We did a unit on dinosaurs that must have resonated with me because I remember my Pterodactyl report. I thought I was quite clever because I knew that the p in Pterodactyl was silent. We also did a unit on Plains Indians. We learned that Plains Indians lived in teepees on the plains and they hunted buffalo. We fashioned paper teepees into an Indian village. (It would not be until University that I would learn anything of more significance about Indian people.) We also did a unit, I would guess that it was in Social Studies, about different cultures in the world. We were taught that in Canada we are multicultural; we are not a melting pot like the United States. At least that's what they taught us. So I went home and asked my mom what we were. "Well," she said, "on Dad's side, his dad was German and his mom is Scottish. And on my side Grandma and Grandpa were French."

\section{"Who are you?" \\ "On my dad's side I am German and Scottish. On my mom's side I am French." At least that's what they told me.}

There are French roots on my Métis side and my great grandparents spoke French. French was preferable to Indian because to be French is to be on the white side, the dominant side. We receive messages loud and clear both on what is said and on what is not said. "We fashion our identities by piecing together all the verbal and nonverbal messages we receive from others" (Miller Marsh \& Turner-Vorbeck, 2010, p. 2). Although it was never said, the implicit message that I received was, do not talk about the Cree side. Yet, I always wanted to speak Cree.

I would ask my mom to teach me Cree, but my mom could not teach me because she only knew "a little bit of Cree." At least that's what she would say when I asked. My grandma would come over and visit and they would sit in the living room, drinking coffee and smoking cigarettes. I would play quietly on the floor with coloring books, buttons, or paper dolls. When they wanted to say something they did not want me 
to hear, they would speak in Cree. I would listen very closely because some words have no Cree word. I would listen for the English words that would be mixed in, usually just names of people or places or odd words and I would try to figure out what they were talking about. They also used to whisper loudly to each other when they were talking about someone, as if that person could hear them. Usually they would start talking about someone and they would start to whisper and then they would start whispering in Cree. It sounded beautiful to me.

\section{"Who are you?" \\ “Well I'm French. But we don't speak French, we speak Cree." At least that's what they told me.}

Many years later, as an adult, I asked my mother why she did not teach me Cree. She said, "Because it was not an advantage." I would agree that, at that time, she was right. Identifying with the dominant culture has privileges and advantages. The higher up in social institutions, the more people you find from the dominant culture. Logic would dictate that if you want to be in a position of power within any institution, it would be easier to attain if you were a member of the dominant culture. It benefits me to identify myself as white and if I spoke Cree it would be harder to identify as white. I have lost the language of my people, my birthright, because to speak it is a disadvantage. I am not the only one. Ukrainian, German, Spanish, Italian, many of these languages in Canada are lost to the younger generation. I am reminded of the melting pot theory. Who would believe that we could take all cultures, all languages and melt them down and out of this mass would come white, English culture. Why would we ever believe that this was a good thing?

\section{Here You Are This}

What if your reflection changed from place to place? In one place your reflection was this and in another place it was something else and in another place something else? Place matters. "In addition to ethnic identity, the racial composition of the neighborhood, peer group, cohabiting family members, and school all had significant impacts on racial identification" (Herman, 2004, p. 744). My hometown was a unique place in many respects. The community was in the far north, only accessible by plane, boat, and a road in the winter. It was a large community of about 4,000 people. I recall many people in the community, of my parents' age, being new Canadians. People came from provinces throughout Canada as well as other countries. The largely outnumbered local population consisted of Métis families, like my mother's, as well as some Dene and Cree families. My family was quite well known in the community. My father was the 
mayor for a couple of years and a member of the Knights of Columbus. Although my mother is Métis and looks Indian, no one ever treated my mother like an Indian. From my perspective, racial identity was ignored. It was a non-issue and I did not see racism when I was growing up.

My sixth birthday party was special. I was in school by then so I could invite friends from school. Birthday parties in my day were simple affairs. Parties were held in your home. You ate cake and ice cream. You opened presents. You played games with your friends and after a few hours your friends went home. I have a picture taken at my sixth birthday party. I am sitting around the table with all of my friends with the birthday cake in front of me. The candles are lit and if I listen closely enough I can hear my friends singing Happy Birthday. In a few moments my mother will cut the cake. My greatest wish at that moment was that I would be lucky and I would find in my piece of cake a coin wrapped in foil. I am dressed like all of the other little girls in a short red party dress. My hair is styled, like my friends, in two pony tails at either side of my head. As I look at the picture, I realize that all of my friends in this picture are white.

\section{"Who are you?" \\ "I am a proud Cree Indian but I speak English and have many white friends." At least that's what they told me.}

I feel very fortunate, in many ways, to have grown up in this environment. I had only positive feelings about being Indian because I was never subjected to racism. I did not know that Indian people could be treated differently. Ironically, I was proud to be Indian because I was not treated like an Indian.

\section{But Here You Are This}

My hometown was based on one industry: mining. When the price of uranium plummeted, the mine closed and people packed up and left. We moved to the city the summer before I started Grade 10. In the city no one knew me or my family. In the city I was treated much the same way as I had always been treated. I do not look Indian, but my mom does. "There are different challenges for those Aboriginal people who are visibility identifiably Aboriginal and those who are not" (St. Denis, 2007, p. 1083).

On a Sunday, during the summer before I was to start school, my mom and I spent the morning at the Bay in downtown Saskatoon. On the second floor was a beauty salon where my mother got her hair cut and styled. We lingered through the store, 
picking up a few things on our way out. I remember it was quite busy and when it came time to pay we ended up in a long lineup. The teller was a young lady, in her early twenties, who was exceptionally friendly. She began each transaction with a cheerful, "Good afternoon. Will that be cash or will you be putting that on your Bay card today?" This was followed with many smiles and general conversation as she rang in the purchases. Waiting in line I commented, in my teenage vernacular, on how friendly and perky the teller was, "Someone had their happy pills today." My mother replied that the Bay takes customer service very seriously and it was something that was always stressed when she worked at the Bay in our hometown. I wandered a few feet away to look at something that had caught my eye as my mother stepped up and placed her purchases on the counter. The teller's behavior instantly changed. There was no smile and in fact there were no words at all. She barely glanced at my mother and throughout the whole interaction, she looked above or below or beside my mother, as if just looking at my mother was somehow painful. I was shocked. It felt like someone had punched me in the gut and then pulled out my heart. She was treating my mother this way because she looked Indian. This was so blatantly obvious to me, yet hard to understand. I had never seen anyone treat my mother this way and it forced me to look at my mother through a new lens. I hung back, rooted to the floor, unable to move forward. After ringing in the purchases, the teller, dryly without looking at my mom said, "\$18.45." My mom purposefully placed her purse on top of the counter, opened her purse, took out her wallet, took out her Bay card and said, "I would like to put that on my Bay card." The young teller rolled her eyes, snorted, and said rather disgustedly, "You need to tell me before I total your purchases if you are using your Bay card. I have already rung it in." To which my mother replied, "I worked at the Bay for many years and I know this. You asked everyone in line before me if they wanted to pay cash or put it on their Bay card, but you didn't ask me. You didn't say anything to me. So now you will have to do an override." She was making a point and she said this in a respectful manner. But in the end, it seemed to matter little. The young lady, oblivious to her own racial prejudice, merely rolled her eyes and began pushing buttons. The people in line behind my mother also huffed, rolled their eyes, and looked generally disgusted at my mother. You could read their thoughts, "Crazy lady, troublemaker, quack..."

"Who are you?"

"I am Indian. Like my mother."

At least that's what I told me. 
Prejudice and racism are strange things. White people will often say that they do not see any racism, yet Indian people will often say that they see a great deal of racism. Our perception is based on our lens. Perhaps you can only see racism when you have been on the receiving end of racist behavior and have felt what that feels like. I do not believe that most people are intentionally racist. Our actions stem from our beliefs: people are only reflecting what they have been taught in their families, in their schools and in their community. We can change racist behavior by changing beliefs in our communities, in our schools, and in our families.

I am Indian and I am white, yet often I am forced to choose. In talking about this choice Poston (1990) had this to say, "Individuals at this stage are pushed to choose an identity, usually of one ethnic group. This can be a time of crisis and alienation for the individual" (p. 153). I am not sure if it is a true choice because I cannot be one without the other. I am Indian and I am white. I am both. At different times, in different places and with different people, I may feel more connected to one side but both sides are always there. I do not think that I could cut out half of who I am. I can only be both.

\title{
No Really....Who Are You?
}

I started this paper talking about wanting to create balance. I struggle because although I see both sides of me reflected as one, many people see only one side reflected. No matter what I tell myself, it is hard to get away from what other people reflect. People see me as white or Indian, but not both. I prefer the idea of a third space.

A third space offers a place where hybridity, or being mixed-race, can be experienced holistically and celebrated as central to Métis culture. A third space offers an escape from Cartesian duality and polarized thinking, from being stuck between being a White person with some Indian blood or a Native person with some white ancestors. (Richardson, 2006, p. 66)

I think I see myself in that third space when I just am. When I am not asked to choose and when I do not have to think about it. Then I am one. Perhaps one day others will see me as this way too.

\author{
Who are you? \\ I am a German, Scottish, Cree, Métis, Indian woman. \\ I am not one or more of any of these. \\ One day this is what they will tell me.
}




\section{What Did They Tell You at School?}

Through this reflective learning journey, I have come to understand that identity formation can be complex and difficult. During my years in school there was little that acknowledged the Indian side of my identity. The only time that I can recall when Indian people were even mentioned was in Grade 4 when we did a unit of study on Plains Indians. The fact that this is the only memory that stands out speaks volumes. Although the history and culture of Indian people was largely ignored, I was fortunate that my family and my community affirmed my ethnicity in a positive manner. For children who do not have a positive family or community connection, it is crucial that schools affirm children's identity with positive messages if children are to grow up proud of who they are. I wish there had been more Indian content included in the curriculum when I was in school and I wonder what effect this would have had on my identity.

I have observed positive changes in schools since I was a student. Many school divisions have dedicated resources and personnel to ensure that Indian perspectives, history, and culture are included in programming, and there is a growing understanding that this First Nations, Métis, and Inuit content should be a golden thread that is woven into everything we do in school. Professional development opportunities offer educators opportunities to learn First Nation worldviews and perspectives. Within the school environment, educators are able to build positive images of Indian people and, in this way, influence the beliefs through which children see Indian people. I was recently in a Grade 1 classroom in which the teacher had worked very intentionally to weave Indian content throughout and within the entire curriculum. The children were engaged in a class discussion regarding stewardship of the earth and environmental concerns and issues. As I sat there, a small girl spoke very eloquently and respectfully about Indian people. To hear this child speak in such a knowledgeable, respectful manner about Indian people filled my heart with joy. If we continue to intentionally include multiple perspectives in our curriculum then perhaps all future generations will grow up with a positive sense of themselves and who they are.

Who are you?

I am me and that is wonderful!

At least that's what they told me. 


\section{Epilogue}

My husband is a status Indian and a member of the Wahpeton Band. Our three sons are status Indians and members of the Wahpeton band. Because of the way in which Indian status and band membership is legislated federally, my grandson does not have any Indian status and he is not a member of the Wahpeton band. If they take away your status and your band membership, what does that do to your identity?

"So your father was treaty and your grandpa and your great grandpa were treaty but you are not treaty?"

"Yes"

"But what about the grass growing and the rivers flowing'?"

I know, but this is what they told me.

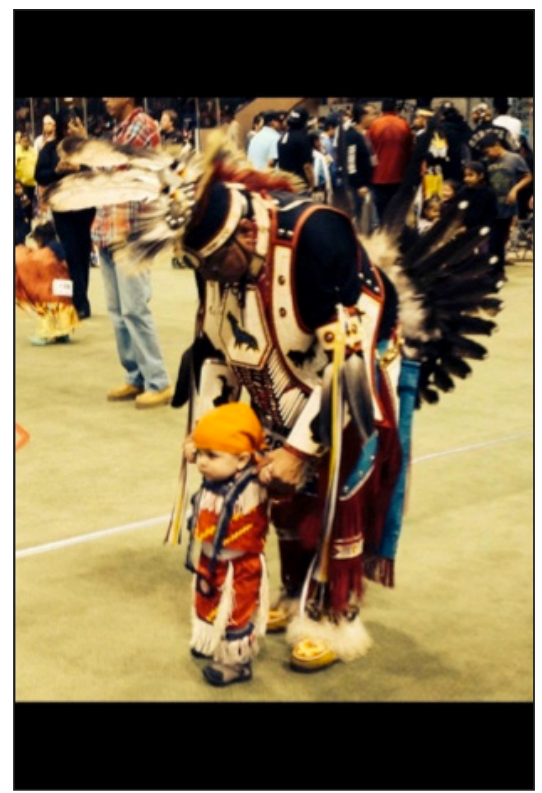

Fig. 1: My grandson dancing with Grandpa at the thanksgiving Pow Wow in Prince Albert, Saskatchewan, Canada, in 2013. What will he answer when someone asks, "Who are you?" 


\section{Note}

1. Stated in the Declaration of Treaty 6, 7, and 8 First Nations, guaranteeing that the promises between First Nations and non-First Nations people would be honoured "as long as the sun shines, rivers flow and the grass grows." (http://www.treatycouncil. org/PDF/Treaty_Rights_and_Health_Resolution.pdf)

\section{References}

Chavez, A. F., \& Guido-Dibrito, F. (1999). Racial and ethnic identity and development. New Directions For Adult And Continuing Education, 84, 39-47.

Herman, M. (2004). Forced to choose: Some determinants of racial identification in multiracial adolescents. Child Development, 75(3), 730-748.

King, T. (2012). The inconvenient Indian: A curious account of native people in North America. Canada: Anchor Canada.

Markus, H. (1977). Self-schemata and processing information about the self. Journal of Personality and Social Psychology, 35(2), 63-78.

Miller Marsh, M., \& Turner-Vorbeck, T. (2010). Introduction. In M. Miller Marsh \& T. TurnerVorbeck (Eds.), (Mis) understanding families: Learning from real families in our Schools. New York: Teachers College Press.
Poston, W. S. C. (1990). The biracial identity development model: A needed addition. Journal of Counseling and Development: JCD, 69(2), 152-155.

Richardson, C. (2006). Métis identity creation and tactical responses to oppression and racism. Variegations, 2, 56-71.

Rummens, J. A. (2001). Canadian identities: An interdisciplinary overview of Canadian research on identity. Halifax, NS: Department of Canadian Heritage.

Sidanius, J., \& Pratto, F. (1993). The inevitability of oppression and the dynamics of social dominance. In P. Sniderman, P. Tetlock, \& E. Carmines (Eds.), Prejudice, politics, and The American dilemma (pp. 173-201).

St. Denis, V. (2007). Aboriginal education and anti-racist education: Building alliances across cultural and racial identity. Canadian Journal of Education, 30(4), 1068-1092.

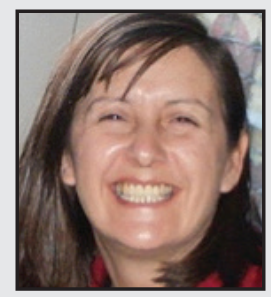

Andrea Fiss has been an educator for over 20 years, working with our youngest learners in vulnerable communities. She is currently an educational consultant with the Saskatoon Public School Division. She graduated from the University of Saskatchewan with a Bachelor of Education and has returned to the University of Saskatchewan as a candidate in the Masters of Education program in the Department of Curriculum Studies. Andrea grew up in Northern Saskatchewan; she loves the North and its people. 